DE

M E D I C I N A

T R O P I C A L

$\mathrm{DE}$

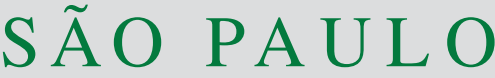

JOURNAL OF THE SÃO PAULO INSTITUTE OF TROPICAL MEDICINE

${ }^{1}$ Universidade Federal da Paraíba, Programa de Pós-Graduação em Enfermagem, João Pessoa, Paraíba, Brazil

2Universidade Federal da Paraíba, Departamento de Enfermagem Clínica, João Pessoa, Paraíba, Brazil

Correspondence to: Emanuelle Malzac Freire de Santana Universidade Federal da Paraíba, Programa de Pós-Graduação em Enfermagem, Cidade Universitária, s/n, CEP 58035-000, João Pessoa PB, Brazil

Tel: +55 83988251949

E-mail: manumalzac@gmail.com

Received: 22 January 2018

Accepted: 2 May 2018

\section{Factors associated with the development of physical disabilities in Hansen's disease}

Emanuelle Malzac Freire de Santana', Karen Krystine Gonçalves de Brito', Ester Missias Vilaverde Antas ${ }^{1}$, Jordana de Almeida Nogueira ${ }^{1}$, Oriana Deyze Correia Paiva Leadebal ${ }^{1}$, Mirian Alves da Silva², Marta Miriam Lopes Costa', Maria Júlia Guimarães Oliveira Soares ${ }^{1}$

\section{ABSTRACT}

Hansen's disease is probably the human disease that causes more damage. The aim of this study was to investigate the association between the occurrence of the association of grade 1 and 2 physical disabilities in Hansen's disease, as well as implications of joint analysis and strength of association with independent demographic and clinical variables. This is a quantitative, descriptive, retrospective, population-based and documentary study developed from 2009 to 2014 in a Hansen's disease reference center in Joao Pessoa, PB. It involved 414 medical records, the diagnosis and discharge data on socio-demographic, clinical and simplified neurological evaluation variables. Data were analyzed using descriptive (absolute frequency and percentage) and inferential (Chi-Square and Prevalence Ratio (PR) statistics techniques. Both in the diagnosis and discharge, low education level, multibacillary classification and presence of affected nerves were statistically associated to the development of disabilities $(\mathrm{p}<0.05)$. The gender showed association only at discharge $(\mathrm{p}<0.05)$. Male gender, low education level, multibacillary classification and presence of affected nerves were identified as factors associated with the development of disabilities, and the individuals were more likely to develop disabilities at discharge. There is a need for development of surveillance actions for the population group identified for the detection and early treatment of the disease. Higher chances of developing disabilities in the discharge period makes the promotion of guidelines that standardize the care of these individuals imperative.

KEYWORDS: Hansen's disease. Risk factors. Prevention and control. Secondary care.

\section{INTRODUCTION}

Hansen's disease is probably the human disease that causes more damage. Estimates suggest the existence of 2 to 3 million people in the world living with sequels resulting from this disease ${ }^{1}$. In Brazil, it presents itself as a public health problem, in view of the large number of notifications of new cases diagnosed with stage 2 disabilities (S2D)².

The S2D occur when there are deformities seen in the body parts affected by Hansen's disease, as claws, bone reabsorption, muscle atrophy, contractures and wounds, which can be observed in the hands and feet; lagophthalmos, ectropion and entropion, trichiasis, corneal opacity and iridocyclitis in the eye ${ }^{3}$. In addition to limiting the performance in activities and restrict the social participation, these deformities can also predispose the stigma reflecting psychological, economic, and social losses ${ }^{4}$. 
Brazil is the second in the world scene in number of notifications of new cases with S2D, registering 1,752 cases in 2015. Despite the high indices recorded, this indicator is showing a declining trend over the years, observing a decline of $29 \%$ in the last 10 years $(2005-2015)^{2,5}$.

In order to further reduce the burden of Hansen's disease in Brazil and in the world, the current strategy for combating the disease proposes as one of its goals for the year of 2020 , the reduction in the rate of individuals with S2D to $<1$ case per million inhabitants, which corresponded to 2.1 cases per million inhabitants in 2015. For both, actions are proposed to strengthen the awareness of individuals about the disease, early detection through the active search of cases, immediate commencement/adherence to treatment and the improvement of prevention and management of disabilities ${ }^{2,6}$.

Although several factors associated with the development of disabilities are addressed in scientific articles, it is clear that studying the magnitude of each factor, alone or associated, the chances of an individual illness, or even worsen, empowers managers, health professionals and researchers in the implementation of strategies directed to health care.

Thus, it is essential to strengthen interventions that prevent illness and the worsening of disabilities, bearing in mind that despite all diagnostic and therapeutic procedures performed in our country, weaknesses in the health services that favor the disease development and problems regarding their early detection are still found.

There are several factors that affect the control of Hansen's disease, such as socioeconomic, emotional, environmental and biological factors ${ }^{7}$ and knowledge about these, at local and tate levels, are essential to identify and direct attention to the health of vulnerable groups.

Considering that research involving this context are still scarce in Brazil, it is expected that this study can subsidize managers and health professionals in the planning of actions directed to individuals who have a chance of developing disabilities, prioritizing actions for monitoring and improvement of the plans that subsidize their prevention. For both, the objective of this study was to investigate the association between the occurrence of grade 1 and 2 physical disabilities in Hansen's disease, the implications of joint analysis and the strength of association with independent demographic and clinical variables.

\section{MATERIALS AND METHODS}

This is a descriptive, retrospective, population-based and documentary source study, quantitatively conducted between 2009 and 2014 with records of patients with diagnosis of Hansen's disease treated at a reference center specialized in the treatment of disease in the city of Joao Pessoa, Paraiba, Brazil.

This service has been a reference for health dermatology care since the end of the 1980s, attending approximately 150 cases of leprosy patients coming from several municipalities of the State. Due to the weaknesses of basic care, the service performs both routine diagnosis and receives cases of difficult diagnosis and management, carried out by means of spontaneous demand and through referrals. The care of patients is performed by a multiprofessional team composed of medical doctors, nurses, physiotherapists, occupational therapists, psychologists, nutritionists and dentists.

The study population consisted of 485 patients in the metropolitan region of Joao Pessoa, involving 12 municipalities, namely: Alhandra, Bayeux, Caapora, Cabedelo, Conde, Cruz do Espirito Santo, Joao Pessoa, Lucena, Pedras de Fogo, Pitimbu, Rio Tinto and Santa Rita.

As inclusion criteria, the following were established: medical records of patients in the metropolitan region of Joao Pessoa, who started and finished the treatment for Hansen's disease in the reference center and had filled the simplified evaluation of neural functions and complications both in diagnosis and in the rate of cure. Exclusion criteria: medical records of patients with cognitive impairment $(n=4)$, due to inability to perform the neurological simplified assessment; records with incomplete information $(n=61)$; and records of patients who did not undergo the treatment according to the Ministry of Health $(\mathrm{MoH})$ recommended time $(n=6)$ (paucibacillary Hansen's disease - 6 doses at up to 9 months and multibacillary cases -12 doses in up to 18 months). In this way, the study population consisted of 414 records of patients.

Data were collected from January to April 2016 through a structured instrument from the records of the patients, from which demographic variables were extracted (gender, age, educational level and occupation) at admission, as well as clinical variables (operational classification paucibacillary or multibacillary) of the notification form.

The instrument was also composed of information related to the time of diagnosis and the rate of cure from the simplified evaluation of neural functions and complications. The use of this connector is recommended by $\mathrm{MoH}$ and is based on a neurological evaluation to identify the severity of the lesions in the eyes, nose, hands and feet ${ }^{3}$, being an integral part of the assessment made in the service.

Regarding the eyes, information was collected regarding the presence or absence of trichiasis, ectropion, lagophthalmos, sensitivity of the cornea, corneal opacity and visual acuity. In the nose, items related to dryness, wound and perforation of the septum were investigated. To record 
information about hands and feet, data on the presence or absence of hypoesthesia, ulcer, claws, foot or hand fall and bone resorption were used. The number of affected nerves and their classification in ulnar, radial, medial, common fibular and posterior tibial was also recorded.

In each connector, the maximum stage of physical disabilities (SPD) ranging from 0 to 2 was considered. Stage 0 is used when there is no damage present in the eyes, hands and feet, stage 1 corresponds to a decrease or loss of sensitivity and stage 2 refers to the presence of deformities, visibly due to Hansen's disease ${ }^{8}$.

It is noteworthy that in 2016 a technical manualoperational entitled "Guidelines for surveillance, attention and elimination of Hansen's disease as a public health problem" as release, and it contained modified criteria for evaluation of the SPD including the muscular strength as a criterion $^{3}$. However, as the study was carried out from 2009 to 2014 , this amendment was not considered.

Procedures for data collection included purchase requisition from the list of records from customers who were seen in the study period in the sector of epidemiological surveillance of the center of reference for subsequent request of these data at the Medical Files Service and Statistics, responsible for organizing and providing the records. Then, there was the information completion on the instrument.

The obtained data were coded for tabulating in Microbland Excel, and then exported and analyzed by the Statistical Package for the Social Sciences (SPSS) version 20.0 using descriptive statistical techniques (absolute frequency and percentage) and inferential tests (chi-square, prevalence ratios -PR and Fisher's exact test).

The first two tests provided an analysis about the relationship and association estimative between exposure to factors (demographic and clinical variables) and the outcome (the development of disability). It should be emphasized that the significance level used was $5 \%$ $(\mathrm{p}<0.05)$.

For performing the association tests, data regarding the level of education and the clinical form were categorized, so that individuals with basic education (less than eight years of study) were classified as low level of education and those with high school and college (more than eight years of study), as moderate/high.

In the research process the ethical observances contemplated in the guidelines and regulatory standards for research involving human subjects - Resolution 466/12 of the Brazilian National Health Council ${ }^{9}$ were adopted especially with regard to the secrecy and confidentiality of data. The project was approved by the Research Ethics Committee at the Health Sciences Center of the
Universidade Federal da Paraiba, under the protocol 443/14, CAAE 34284414.3.0000.5188.

\section{RESULTS}

Among the participants involved in the study, there was a male predominance (58.7\%), aged 31 to 45 years (27.8\%), basic education as educational level (53.6\%) and classification multibacillary (60.6\%).

In Table 1, it can be observed that, at the time of diagnosis, the variables educational level and operational classification are statistically associated with the development of physical disabilities $(\mathrm{p}<0.05)$. It is emphasized that multibacillary individuals are twice as likely to develop sequelae as paucibacillary individuals.

Table 2 represents the time of discharge, in addition to the aforementioned variables, gender was also significantly associated with the occurrence of physical disabilities $(\mathrm{p}<0.05)$. All the variables that showed significant association with the disabilities were more likely to develop them at discharge compared to the time of diagnosis.

With respect to the types of nerves, both in diagnosis and in the rate of cure, it is possible to observe that the impairment of the ulnar, radial, median, common peroneal and posterior tibial nerves were significantly associated with disability $(\mathrm{p}<0.05)$ (Table 3$)$.

\section{DISCUSSION}

The emergence of disabilities in patients diagnosed with Hansen's disease indicates the presence of some gaps in the disease control, among them the social aspects of individuals. The analysis of this study found that men, low educational level and operational classification multibacillary Hansen's disease are related to the development of disabilities (1 or 2). Have affected nerves, either at diagnosis or at the time the rate of cure was recorded, also configured predisposition to sequels settlement.

For many pathologies, gender has been implicated as a factor associated with the occurrence of morbidities and their worsening. In this study, the male gender was associated with the development disabilities when compared to female, both at the time of diagnosis and at the establishment of the rate of cure. It should be emphasized, however, that the statistical power have configured significant $(\mathrm{p}=0.039)$ only in the discharge period, with probability $30 \%$ higher at this time.

A study in the micro-region of Diamantina, Minas Gerais State, evidenced, in the male population, increased rates of S2D diagnosis (32.4\%), highlighting the late discovery of the disease in these individuals. The authors 
Table 1 - Association of disability stage, demographic and clinical variables at the time of diagnosis. Joao Pessoa, 2016

\begin{tabular}{|c|c|c|c|c|c|c|c|}
\hline \multirow{3}{*}{$\begin{array}{l}\text { Demographic and } \\
\text { clinic variables }\end{array}$} & \multirow{2}{*}{\multicolumn{2}{|c|}{ Total }} & \multicolumn{4}{|c|}{ Incapacity stage } & \multirow{3}{*}{$\mathrm{PR}^{\star *}(\mathrm{IC} .95 \%)$} \\
\hline & & & \multicolumn{2}{|c|}{ Stage (1 or 2 ) } & \multicolumn{2}{|c|}{ Stage 0} & \\
\hline & $\mathrm{n}$ & $\%$ & $\mathrm{n}$ & $\%$ & $\mathrm{~N}$ & $\%$ & \\
\hline \multicolumn{8}{|l|}{ Pacient's gender } \\
\hline Male & 243 & 100 & 103 & 42,4 & 140 & 57,6 & \\
\hline Female & 171 & 100 & 65 & 38,0 & 106 & 62,0 & $1,115(0,876-1,419)$ \\
\hline Total & 414 & 100 & 168 & 40,6 & 246 & 59,4 & \\
\hline \multicolumn{8}{|l|}{ Education level $\left.{ }^{*}\right)$} \\
\hline Low & 222 & 100 & 106 & 47,7 & 116 & 52,3 & \\
\hline Moderate/High & 192 & 100 & 62 & 32,3 & 130 & 67,7 & $1,479(1,155-1,892)$ \\
\hline Total & 414 & 100 & 168 & 40,6 & 246 & 59,4 & \\
\hline \multicolumn{8}{|c|}{ Operational Classification $\left(^{*}\right)$} \\
\hline Paucibacillary & 163 & 100 & 36 & 22,1 & 127 & 77,9 & \\
\hline Multibacillary & 251 & 100 & 132 & 52,6 & 119 & 47,4 & $2,381(1,744-3,251)$ \\
\hline Total & 414 & 100 & 168 & 40,6 & 246 & 59,4 & \\
\hline
\end{tabular}

(*) Significant association $\leq 0,05 .\left({ }^{* *}\right)$ PR $=$ Prevalence Ratio. Source: Research data, 2016.

Table 2 - Association of the disability stage, demographic and clinical variables at discharge. Joao Pessoa, 2016

\begin{tabular}{|c|c|c|c|c|c|c|c|}
\hline \multirow{3}{*}{$\begin{array}{l}\text { Demographic and } \\
\text { clinic variables }\end{array}$} & \multirow{2}{*}{\multicolumn{2}{|c|}{ Total }} & \multicolumn{4}{|c|}{ Incapacity stage } & \multirow{3}{*}{$\mathrm{PR}^{\star \star}(\mathrm{IC} .95 \%)$} \\
\hline & & & \multicolumn{2}{|c|}{ Stage (1 or 2$)$} & \multicolumn{2}{|c|}{ Stage 0} & \\
\hline & $\mathrm{n}$ & $\%$ & $\mathrm{~N}$ & $\%$ & $\mathrm{n}$ & $\%$ & \\
\hline \multicolumn{8}{|l|}{ Pacient's gender $\left(^{*}\right)$} \\
\hline Male & 243 & 100 & 101 & 41,6 & 142 & 58,4 & \\
\hline Female & 171 & 100 & 54 & 31,6 & 117 & 68,4 & $1,316(1,009-1,718)$ \\
\hline Total & 414 & 100 & 155 & 37,4 & 259 & 62,6 & \\
\hline \multicolumn{8}{|l|}{ Education level (*) } \\
\hline Low & 222 & 100 & 105 & 47,3 & 117 & 52,7 & \\
\hline Moderate/High & 192 & 100 & 50 & 26 & 142 & 74 & $1,816(1,378-2,393)$ \\
\hline Total & 414 & 100 & 155 & 37,4 & 259 & 62,6 & \\
\hline \multicolumn{8}{|c|}{ Operational Classification $\left(^{*}\right)$} \\
\hline Paucibacillary & 163 & 100 & 28 & 17,2 & 135 & 82,8 & \\
\hline Multibacillary & 251 & 100 & 127 & 50,6 & 124 & 49,4 & $2,946(2,058-4,216)$ \\
\hline Total & 414 & 100 & 155 & 37,4 & 259 & 62,6 & \\
\hline
\end{tabular}

(*) Significant association $\leq$ 0,05. (**) PR = Prevalence Ratio. Source: Research data, 2016.

emphasize that, generally, men seek health services only for the treatment of a disease, while women, by virtue of the aesthetic aspects and the various programs for their health, pay more attention ${ }^{10}$.

The low educational level, which presented probability $40 \%$ higher of developing disabilities at the time of diagnosis and $80 \%$ in the discharge period, was also an associated factor found by other authors ${ }^{10-12}$, corroborating the findings in individuals who have a lower educational level. The degree of instruction is a determinant factor for the development of SPD, since the knowledge about the disease and the understanding of the guidelines, preventive and therapeutic measures influence the ability for self-care ${ }^{13}$, which is fundamental to the achievement of preventive actions.

Attention should be paid to the level of education of the patients in order to promote the understanding about health education. Through it, individuals become jointly responsible for their treatment, being able to identify 
Table 3 - Association of disability stage and the affected nerves at the time of diagnosis and at the cure discharge period. Joao Pessoa, 2016

\begin{tabular}{|c|c|c|c|c|c|c|c|c|}
\hline \multirow{3}{*}{ Affected nerves ${ }^{(1)}$} & & & \multicolumn{4}{|c|}{ Incapacity Stage } & \multirow{3}{*}{$\begin{array}{c}\mathrm{X}^{2} \text { Association } \\
\text { test }\end{array}$} & \multirow{3}{*}{$\mathrm{PR}^{\star \star}(\mathrm{IC} .95 \%)$} \\
\hline & \multicolumn{2}{|c|}{ Total } & \multicolumn{2}{|c|}{ Stage - (1 ou 2$)$} & \multicolumn{2}{|c|}{ Grau - 0} & & \\
\hline & $\mathrm{n}$ & $\%$ & $n$ & $\%$ & $\mathrm{~N}$ & $\%$ & & \\
\hline UInar & & & & & & & $\mathrm{p}^{(1)}=0,000^{*}$ & \\
\hline Diagnosis & 118 & 100 & 77 & 65,3 & 41 & 34,7 & & $2,123(1,711-2,634)$ \\
\hline Discharge & 84 & 100 & 55 & 65,5 & 29 & 34,5 & & $2,161(1,724-2,707)$ \\
\hline Radial & & & & & & & $\mathrm{p}^{(1)}=0,000^{*}$ & \\
\hline Diagnosis & 60 & 100 & 40 & 66,7 & 20 & 33,3 & & $1,844(1,470-2,312)$ \\
\hline Discharge & 34 & 100 & 24 & 70,6 & 10 & 29,4 & & $2,048(1,583-2,649)$ \\
\hline Median & & & & & & & $\mathrm{p}^{(1)}=0,000^{*}$ & \\
\hline Diagnosis & 95 & 100 & 70 & 73,7 & 25 & 26,3 & & $2,398(1,956-2,941)$ \\
\hline Discharge & 34 & 100 & 24 & 70,6 & 10 & 29,4 & & $2,048(1,583-2,649)$ \\
\hline Common Fibular & & & & & & & $\mathrm{p}^{(1)}=0,000^{*}$ & \\
\hline Diagnosis & 83 & 100 & 56 & 67,5 & 27 & 32,5 & & $1,994(1,613-2,465)$ \\
\hline Discharge & 56 & 100 & 44 & 78,6 & 12 & 21,4 & & $2,534(2,062-3,115)$ \\
\hline Tibial Posterior & & & & & & & $\mathrm{p}^{(1)}=0,000^{*}$ & \\
\hline Diagnosis & 102 & 100 & 71 & 69,6 & 31 & 30,4 & & $2,239(1,816-2,760)$ \\
\hline Discharge & 80 & 100 & 62 & 77,5 & 18 & 22,5 & & $2,783(2,258-3,431)$ \\
\hline
\end{tabular}

(*) Significant association $\leq$ 0,05. (**) PR = Prevalence Ratio. Source: Research data, 2016.

and treat possible alterations in body parts, in addition to performing self-care activities in their daily lives ${ }^{14}$.

Analyzing the clinical aspects, the individuals classified as multibacillary patients presented probability 2 times higher for the incapacities settlement, both at the time of diagnosis $(\mathrm{PR}=2.381)$ and high $(\mathrm{PR}=2.946)$. These findings were similar to the ones of a prevalence study after drug therapy of Hansen's disease discharge ${ }^{15}$, and they found a chance 9 times greater of these individuals to develop sequels when compared with paucibacillary Hansen's disease ${ }^{13}$.

The patients of multibacillary classification, the most important group with ability to infect non treated individuals, presents high bacillary load and are consequently more likely to developing physical disabilities due to illness. When the diagnosis is late, the situation becomes worse due to a higher chance of transmission and the presence of neural complications in the patients ${ }^{16,17}$.

It is noteworthy that the diagnosis and immediate treatment are the more effective measures to reduce the occurrence of sequels of Hansen's disease and until some method of stopping its transmission of the disease arises, individuals will continue to develop sequels ${ }^{18}$.

In the analysis of nervous impairment, the presence of any affected nerve (ulnar, median, radial, common peroneal and posterior tibial nerves) is associated with a 2 times greater possibility to develop any SPD 2 excepting the radial and common peroneal, which showed lower values at the time of diagnosis ( $\mathrm{PR}=1.844$ and $\mathrm{PR}=1.994)$.

One of the justifications for the radial nerve to have a lower probability at the time of the diagnostic evaluation is that it has a more protected location which is only reached after the impairment of the ulnar and median nerves that has a threefold chance of evolving to paralysis. When achieved, the individual is unable to extend the wrist and fingers with the sagging hand. In lesions of the ulnar and median nerves, several abnormalities such as the rise of claws in response to weakness and/or paralysis of the muscles of the hand, as well as the loss of the ability of the thumb opposition can occur ${ }^{8}$.

In the case of the common fibular nerve, the deformity in horse's foot only happens when the two branches of the nerve (shallow and deep) are injured, making the ankle disk in this position, requiring, therefore, a greater impairment until the appearance of the lesion. Even in the lower limbs, feet can also acquire the posture of claw due to lesions in the posterior tibial nerve and consequent impairment of all intrinsic foot muscles ${ }^{8}$.

A study involving the analysis of factors associated with disability, diagnosis showed that individuals who had two or more affected nerve trunks were also 2 times more likely to develop some sequel ${ }^{12}$. Corroborating our findings, Ribeiro 
and Lana ${ }^{10}$ identified the presence of damaged nerves at the time of diagnosis as factors related to the occurrence of S2D diagnosis. If the individual has already nervous impairment at the time of diagnosis, two possibilities can explain it: either the discovery is late, or the clinical form is quite aggressively. Both premises corroborate to identify a framework of rapid deterioration and consequent deformity.

It is important to emphasize that, at the time of discharge, all demographic and clinical variables had a greater probability of developing sequels in this situation. Assuming the justification of this result is difficult due to the various intrinsic factors related to illness, monitoring and aggravation of cases. However, it is possible and urgent to raise questions about why patients who underwent treatment and were discharged as cured have a higher chance of developing disabilities. Among the assumptions that may be involved in this context, it is possible to cite the absence of self-care activities, the development of resistance to drug treatment and the presence of exacerbated inflammatory response to an already existing damage.

$\mathrm{MoH}$ recommends that all individuals are oriented to return after discharge due to healing, according to their needs, and that all information provided to patients in treatment is extended to the post-discharge period, mainly in cases that already have some incapacity, in view of the need for follow-up of the practices of self-adaptation of footwear, treating wounds and surgical rehabilitation ${ }^{3}$.

Regarding the research scenario, patients are followedup while receiving MDT doses, after which the care is discontinued. There is no communication between the referral service, secondary care, and family health units, primary care, nor a health care network established for the care of these individuals.

Surveys reveal weaknesses in continuity of assistance for patients in this period, due to fragmentation of care that compromises the quality of the treatment. Among them, the lack of standardization of this monitoring, which is targeted primarily for the treatment of the reactional states, and hinders the understanding of the clinical situation of affected individuals ${ }^{15,19}$. This fragility in care was also observed during treatment, in view of the worsening of patients' neural function.

A study involving the period after the end of the multidrug therapy reveals that $60.9 \%$ of the patients had some degree of physical incapacity and that $24.9 \%$ had social restriction after an average of 7.5 years of treatment ${ }^{20}$. In another study, conducted in a hyperendemic area of Northern Brazil, it was found that the functional limitation presented by patients in the post-discharge period reflected considerably in the accomplishment of activities and social participation $^{21}$.
Taking into account the increased likelihood of individuals in the post-discharge period that develop permanent sequels, it is necessary to design policies for the creation of a network of health attention seeking a regular, continuous and integral assistance to these patients, with the purpose of preventing physical disabilities and detecting previously reactional states and situations of disease recurrence.

The present study identified as factors associated with the onset of physical disabilities: male gender, low education, operational classification multibacillary and presence of affected nerves. These findings point to the need of a follow-up of follow these groups of individuals.

Another result that deserves attention is the increased possibility of patients to develop sequels in the postdischarge period of drug treatment, indicating the need to promote the guidelines that standardize the care during this period.

Considering that, as long as the Hansen's disease is transmitted, there will be disabilities, it is important to sensitize and empower the multiprofessional healthcare team to adopt as routine the active search for patients with the purpose to diagnose and provide adequate treatment to the new cases, and to maintain surveillance of disability in already treated cases.

Although the spatial determination of the study has been about the same, expanding its methodological scope to other regions of the federation is of great importance, aiming to streamline the process of knowledge and compare data with the results found herewith. The inquiries scored in this study are subject to further research with the aim of expanding the pertinent knowledge of disability.

\section{AUTHORS' CONTRIBUTIONS}

Emanuelle Malzac Freire de Santana: project design, data collection and analysis, article writing; Karen Krystine Gonçalves de Brito: project design, data analysis, article writing, critical review; Ester Missias Vilaverde Antas: critical review; Jordana de Almeida Nogueira, Oriana Deyze Correia Paiva Leadebal, Mirian Alves da Silva and Marta Mirian Lopes Costa: critical review and final approval; Maria Júlia Guimarães Oliveira Soares: guidance and collaboration from project design to final approval.

\section{REFERENCES}

1. Pinheiro MG, Silva SY, Silva FS, Ataide CA, Lima IB, Simpson CA. Conhecimento sobre prevenção de incapacidades em um grupo de autocuidado em hanseníase. REME Rev Min Enferm. 2014;18:895-900. 
2. World Health Organization. Global leprosy update, 2015: time for action, accountability and inclusion. Wkly Epidemiol Rep. 2016;35:405-20.

3. Brasil. Ministério da Saúde. Secretaria de Vigilância em Saúde. Departamento de Vigilância das Doenças Transmissíveis. Diretrizes para vigilância, atenção e eliminação da hanseníase como problema de saúde pública. Brasília: Ministério da Saúde; 2016. [cited 2018 May 2]. Available from: http:// portalarquivos2.saude.gov.br/images/pdf/2016/fevereiro/04/ diretrizes-eliminacao-hanseniase-4fev16-web.pdf

4. van Brakel WH, Sihombing B, Djarir H, Beise K, Kusumawardhani L, Yulihane R, et al. Disability in people affected by leprosy: the role of impairment, activity, social participation, stigma and discrimination. Glob Health Action. 2012;5:18394.

5. World Health Organization. Global leprosy situation. Wkly Epidemiol Rep. 2006;32:309-16

6. World Health Organization. Global leprosy strategy 2016-2020: accelerating towards a leprosy-free world. Geneva: WHO; 2016. [cited 2018 May 2]. Available from: http://apps.searo. who.int/PDS_DOCS/B5233.pdf?ua=1

7. Chaptini C, Marshman G. Leprosy: a review on elimination, reducing the disease burden, and future research. Lepr Rev. 2015;86:307-15.

8. Brasil. Ministério da Saúde. Secretaria de Vigilância em Saúde. Departamento de Vigilância Epidemiológica. Manual de prevenção de incapacidades. Brasília: Ministério da Saúde; 2008. [cited 2018 May 2]. Available from: http://bvsms.saude. gov.br/bvs/publicacoes/manual_prevencao_incapacidades.pdf

9. Brasil. Ministério da Saúde. Conselho Nacional de Saúde. Resolução No 466, de 12 de dezembro de 2012. [cited 2018 May 2]. Available from: http://bvsms.saude.gov.br/bvs/ saudelegis/cns/2013/res0466_12_12_2012.html

10. Ribeiro GC, Lana FC. Incapacidades físicas em hanseníase: caracterização, fatores relacionados e evolução. Cogitare Enferm. 2015;20:496-503.

11. Pieri FM, Ramos AC, Crispim JA, Pitiá AC, Rodrigues LB, Silveira TR, et al. Fatores associados às incapacidades em pacientes diagnosticados de hanseníase: um estudo transversal. 2012;37:22-30.
12. Monteiro LD, Martins-Melo FR, Brito AL, Alencar CH, Heukelbach J. Physical disabilities at diagnosis of leprosy in a hyperendemic area of Brazil: trends and associated factors. Lepr Rev. 2015;86:240-50.

13. Ribeiro Júnior AF, Vieira MA, Caldeira AP. Perfil epidemiológico da hanseníase em uma cidade endêmica no Norte de Minas Gerais. Rev Bras Clin Med. 2012;10:272-7.

14. Duarte LM, Simpson CA, Silva TM, Moura IB, Isoldi DM. Selfcare actions of people with leprosy. J Nurs UFPE On Line. 2014;8:2816-22.

15. Monteiro LD, Alencar CH, Barbosa JC, Braga KP, Castro MD, Heukelbach J. Incapacidades físicas em pessoas acometidas pela hanseníase no período pós-alta da poliquimioterapia em um município no Norte do Brasil. Cad Saude Publica. 2013;29:909-20.

16. Araújo e Araújo AE, Aquino DM, Goulart IM, Pereira SR, Figueiredo IA, Serra HM, et al. Neural complications and physical disabilities in leprosy in a capital of northeastern Brazil with high endemicity. Rev Bras Epidemiol. 2014;17:899-910.

17. Brito AL, Monteiro LD, Ramos Júnior AN, Heukelbach J, Alencar CH.Temporal trends of leprosy in a Brazilian state capital in Northeast Brazil: epidemiology and analysis by joinpoints, 2001 to 2012. Rev Bras Epidemiol. 2016;19:194-204.

18. Cross H. The prevention of disability as a consequence of leprosy. Lepr Rev. 2015;86:208-12.

19. Barbosa JC, Ramos Júnior AN, Alencar OM, Pinto MS, Casrro CG. Atenção pós-alta em hanseníase no Sistema Único de Saúde: aspectos relativos ao acesso na região Nordeste. Cad Saude Colet. 2014;22:351-8.

20. Castro LE, Cunha AJ, Fontana AP, Castro Halfoun VL, Gomes MK. Physical disability and social participation in patients affected by leprosy after discontinuation of multidrug therapy. Lepr Rev. 2014;85:208-17.

21. Monteiro LD, Alencar CH, Barbosa JC, Novaes CC, Silva RC, Heukelbach J. Limited activity and social participation after hospital discharge from leprosy treatment in a hyperendemic area in north Brazil. Rev Bras Epidemiol. 2014;17:91-104. 